\title{
A redropelo: cuerpo locuaz y lenguaje poético de la modernidad*
}

\author{
José María FERNÁNDEZ CARDO \\ Universidad de Oviedo \\ cardo@uniovi.es \\ ORCID: 0000-0003-2566-0040
}

\begin{abstract}
Cuerpo locuaz de Amelia Gamoneda es un libro que, como cabría colegir del propio título, habla de muchas cosas, y casi todas ellas esen-

AMELIA GAMONEDA

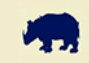

\section{Cuerpo locuaz}

POÉTICA, BIOLOGÍA Y COGNICIÓN ciales para tratar de responder a una pregunta fundamental dentro de las ciencias humanas: ¿qué es poesía?, ¿qué es y cómo funciona el lenguaje poético? o ¡cómo hacen los poetas? Y, sobre todo, en ese espacio histórico, que ocupa ya más de un siglo y medio, y hemos dado en nombrar de la poesía moderna, identificable con algunas prácticas poéticas que siguieron a las primeras manifestaciones del romanticismo, a partir de la segunda mitad del siglo XIX. La autora, como filóloga y profesora de literatura francesa, conoce bien la incidencia en la modernidad de los poetas franceses que abrieron el cauce de ese flujo que se inicia con Baudelaire, pasa por Rimbaud y Lautréamont, se nutre de Verlaine y vierte en Mallarmé, hasta desembocar en las vanguardias, el surrealismo y todo un siglo de poesía hasta nuestros días. Pero, con el ánimo de que el lector no se llame a engaño, conviene señalar aquí que Amelia Ga-
\end{abstract}

* A propósito del libro de Amelia Gamoneda, Cuerpo locuaz. Poética, biología y cognición (Madrid, Abada Editores, 2020, col. «Lecturas de Teoría Literaria», 252 pp. ISBN 978-84-17301-55-2). 
moneda no trata solo de poesía francesa; siendo como es una gran conocedora de la poesía española actual, no pierde la ocasión de convocar en las páginas de su libro la obra de poetas contemporáneos espańoles de referencia.

Los capítulos que lo componen inciden o retoman, pero desde una perspectiva bien distinta, algunos centros de interés que la crítica de inspiración estructuralista del pasado siglo envolvió en el celofán de nociones tales como la connotación, la ambigüedad del lenguaje literario o el texto intransitivo. Estos y otros términos, por entonces usuales en algunos medios, evocaban la dificultad de la lectura, el divorcio aparente con la referencia y, en definitiva, el problema de la representación, lo que es lo mismo que decir la mala relación del texto poético con la mímesis. La autora de Cuerpo locuaz no ha perdido de vista la tradicional pareja antagónica de mimesis/poiesis, pero reformulando ahora el segundo término de la oposición como autopoiesis y trasladándolo desde el campo de la biología, con la intención de evocar una concepción del lenguaje humano en el que se presenta el modo de conocimiento del animal privado de logos, "el modo de conocimiento de los aloga. Un lenguaje humano que precisamente por tentar la parte de su inexistencia puede experimentar su propio surgimiento. Y que incluye en su seno la escena de su surgimiento: que es autopoiético tanto en sentido literario como en sentido biológico" (p. 22).

El seguidor de la trayectoria crítica de Amelia Gamoneda, porque de verdadera trayectoria se puede hablar a poco que se consideren sus títulos anteriores, encontrará una relación gradual de serie entre este libro y el inmediatamente precedente: Del animal poema. Olvido García-Valdés y la poética de lo vivo (2016), ensayo que se nutre de los vínculos del lenguaje con la vida "biológica", situándose en la débil frontera que separa, a veces, y aproxima, otras, al hombre del animal. El cuerpo en ese libro ocupaba ya un lugar de privilegio desde las primeras páginas, en las que la autora se detenía en el comentario de uno de los títulos de la obra de Olvido GarcíaValdés, La poesía, ese cuerpo extraño, y sostenía que "la poesía es un cuerpo propio que ha devenido un cuerpo extrańado y que recibe una herencia de esa entidad biológica de la que proviene".

En el comienzo de su trayectoria como crítica e investigadora Amelia Gamoneda se dedicó, y en ello fue pionera en España, al estudio de la narrativa de Marguerite Duras, sobre la que publicó un voluminoso libro titulado Marguerite Duras, la textura del deseo (1995), y del que ahora conviene aquí traer a colación al menos los títulos de tres de sus capítulos: "El cuerpo abierto", "Trazado oscilante del deseo sobre el cuerpo" y "Texto: el cuerpo de la voz". A la vista de las informaciones que preceden, el lector puede disponer ya de los elementos necesarios para saber que la palabra del cuerpo y la locuacidad de éste no constituyen una imagen ocurrente de la autora en los últimos tiempos, sino una constante en su búsqueda interpretativa de los elementos de base del lenguaje poético (desde la década de los cincuenta del siglo pasado en Francia, no hay evidencia de que, a partir de los denominados textos del 
"nouveau roman", la narrativa y la poesía discurran por caminos divergentes). Bien se diría que ya por entonces el cuerpo estaba en la punta de la lengua...

La poesía, como lenguaje vivo, desde la perspectiva del último libro de Amelia Gamoneda objeto de esta reseńa, se sitúa en una zona que la autora califica de "subsimbólica”, en el reverso de la expresión inteligente; la poesía es una experiencia real que se desplaza entre lo sensible y lo inteligible, que recorre un trayecto "a redropelo", retomando el camino casi olvidado de vuelta a los orígenes mismos del lenguaje (vid. pp. 6-7). El lenguaje poético, como han puesto de manifiesto los estudios críticos más perspicaces en materia de géneros literarios, desde mediados del siglo XX (Hamburger, 1957), no representa, sino que presenta. Pero la originalidad del enfoque de Amelia Gamoneda es que aborda la cuestión ab initio, desde la misma génesis material (corpórea) del lenguaje de los humanos, en términos evolutivos y cognitivos: desde la neurociencia y la biología, ya que su perspectiva de análisis es epistemocrítica, es decir que aborda el lenguaje de la poesía con base en los descubrimientos científicos recientes que tratan de la localización y de la producción del lenguaje en el cerebro. Esta perspectiva es la que ha dado cobertura metodológica, desde hace casi dos lustros, a los trabajos que publica, además de ser la promotora del grupo de investigación ILICIA (Inscripciones Literarias de la Ciencia).

Como cabría esperar, y siempre que de lenguaje poético se trata, no obvia la cuestión esencial de la relación de analogía y la metáfora, cuyo componente y compuesto ella reformula en términos de metáfora-fuente y metáfora-meta. La metáfora tiene la capacidad para comunicar una experiencia, pero no la de proporcionar su comprensión. La poesía actual, escribe Amelia Gamoneda, "no es un acertijo de dominios meta de la metáfora, sino una comunicación de experiencia perceptiva y emocional y por tanto una propuesta de cognición encarnada" (p. 52). El dominio meta obliga al dominio fuente a hacer "gestos de lengua":

Obliga al lenguaje a hablar con gestos que sean legibles como experiencia perceptiva y emocional. En el lenguaje poético, la experiencia presiona al lenguaje, le obliga a ofrecerse de modo que pueda ser leído como gesto. Le pone en situación de simular al ser vivo. Y no a cualquiera, sino a uno que percibe, que se mueve, que sufre emociones (p. 52).

La recepción desde esta concepción de la poesía, de la poesía que lo es de verdad, convierte al lector en el protagonista, al ser el sujeto que experimenta el sentido y las emociones suscitados por el texto; es a él a quien le corresponde la interpretación $y$, en consecuencia, la responsabilidad de la producción del sentido. Con toda firmeza señala la autora: "Esta es la trama de todo poema -hable de lo que hable-: cómo la experiencia de lectura genera sentido. O si no, no es un poema" (p. 8). Convendremos una vez más que la poesía y el poema no dejan de ser formas de extrañamiento del propio yo y del lenguaje: ya lo decía Rimbaud que yo no era yo, sino otro, pala- 
bras que Riffaterre a su modo refrendaba en La production du texte (1979) al hablar de la función de la poesía como experiencia de alienación. La suerte de la poesía parece que quedó definitivamente echada desde aquella enfermiza flor baudelairiana, la que situaba la referencia de lo bello en el ambiguo espacio de la tautología: la Belleza es bella, como un sueño de piedra...

El libro de Amelia Gamoneda consta de dos partes sucesivas y diferenciadas, "Propuestas Teóricas" y "Propuestas de Lectura”. En la primera de ellas encontrará el lector el cuerpo de teoría poética relacionado con la preconsciencia, la evolución biológica y las funciones cognitivas del cerebro; y en la segunda, el cuerpo de poesía, que no solo se conforma con ilustrar y dotar de sentido complementario a la parte primera, sino que añade lecturas -interpretaciones- insólitas, escritas con la destreza y la pericia de quien es frecuentadora asidua de esa clase de textos. En la antología comentada e interpretada que es esta parte segunda, en nada secundaria y ancilar con relación a la precedente, se suceden los estudios analíticos de poemas (y en ocasiones hasta de un solo verso) de Baudelaire, Verlaine, Breton y Éluard, el texto revelación de la poética rimbaldiana, la obra del poeta Claudio Rodríguez y un único libro poético de Antonio Gamoneda, singular por su título y por su contenido, Libro de los venenos. Corrupción y fábula del Libro sexto de Pedacio Dioscórides y Andrés Laguna, acerca de los venenos mortiferos y de las fieras que arrojan de si ponzoña (2006).

El Libro de los venenos le sirve a la autora para configurar una suerte de apoteosis metafórica con relación a su propio trabajo, centrado en la locuacidad del cuerpo, para situarse ahora en el espacio temático de la corrupción que aguarda a los cuerpos, a la que el lenguaje tampoco escapa: a través de la manipulación intertextual el poeta ha transformado un lenguaje científico de referencia dudosa en lenguaje poético que se desliza en medio de referencias fantásticas, si no del todo irreales -el concepto de ambigüedad referencial se queda corto-. En palabras de la autora "en la reescritura algo muere y algo se crea: es propiamente un proceso de envejecimiento del cuerpo" (p. 208), ya que "mientras hay corrupción hay vida en el texto" (p. 209).

Y por si al lector le quedara alguna duda de cuál es el planteamiento teórico del libro en relación con el lenguaje poético, en la clausura del trabajo, a modo de coda, se orienta su atención hacia las prácticas de laboratorio -que es el campo de experimentación por excelencia de los estudiantes de Ciencias-, pero no un laboratorio cualquiera, sino un laboratorio de fotografía, donde gracias a las sales de plata ${ }^{1}$, es posible observar cómo de manera gradual van tomando cuerpo las metáforas, porque la propuesta titular de Amelia Gamoneda para el capítulo que cierra el libro es precisamente "Laboratorio de Metáforas. Fotografía y Pensamiento Poético". La fotografía vendría a ilustrar el funcionamiento del lenguaje poético, dentro del enfoque metodo-

\footnotetext{
${ }^{1}$ Ángeles González Fuentes publicó en 2014 un poemario titulado Sales de plata, donde el texto poético y la imagen fotográfica mantienen una singular relación.
} 
lógico de la autora, en la medida en que la producción del sentido propia del lenguaje referencial pierda la condición de la "biunivocidad", porque durante el revelado "la mano se dedica a meter el dedo en el ojo" (p. 240). En el proceso de la creatividad literaria, y también fotográfica, a la luz de las enseñanzas de la moderna neurociencia, lo que vendría a resultar es que la actividad combinatoria de las neuronas guarda similitudes estructurales con el funcionamiento metafórico y la fluctuación del sentido que caracterizan el lenguaje de la poesía.

Estoy seguro de que la lectura atenta de este corpus textual le proporcionará al lector todos los útiles necesarios para la escucha poética del cuerpo real. Esta investigación de Amelia Gamoneda tiene todos los visos de convertirse en un libro imprescindible para la comprensión del lenguaje poético de la modernidad. ¡Para empezar basta con ceńirse el "delantal" - palabra que da título al íncipit del libro- y adoptar la disposición conveniente para el trabajo, en la cocina del sentido!

\section{REFERENCIAS BIBLIOGRÁFICAS}

GAMONEDA, Amelia (1995): Marguerite Duras, la textura del deseo. Salamanca, Ediciones Universidad de Salamanca.

GAMONEDA, Amelia (2016): Del animal poema. Olvido García-Valdés y la poética de lo vivo. Oviedo, KRK Ediciones.

Gamoneda, Antonio (2006): Libro de los venenos. Corrupción y fábula del Libro sexto de Pedacio Dioscórides y Andrés Laguna, acerca de los venenos mortiferos y de las fieras que arrojan de sí ponzoña. Madrid, Ediciones Siruela.

GONZÁLEZ FuENTES, Ángeles (2014): Sales de plata. Oviedo, KRK Ediciones, col. «Octavo mayor».

HambuRger, Käte (1957): Die Logik der Dichtung. Stuttgart, Ernst Klett. Trad. ingl. The Logic of Literature, 1973.

RIFFATERRE, Michael (1979): La production du texte. París, Seuil. 